\title{
Sorting Out Mechanical and Psychological Effects in Candidate Elections: An Appraisal with Experimental Data ${ }^{\mathrm{i}}$
}

\author{
Karine Van der Straeten \\ Toulouse School of Economics (CNRS-GREMAQ) \\ 21 Allée de Brienne , 31000 Toulouse, France
}

Tel: 335611286 03, E-mail: karine.van-der-straeten@tse-fr.eu

\section{Nicolas Sauger}

Sciences Po Paris (Centre d'études européennes)

27 rue Saint-Guillaume, 75337 Paris Cedex 07, France

Tel : 331454983 52, E-mail: nicolas.sauger@sciences-po.fr

\author{
Jean-François Laslier \\ Ecole Polytechnique (Département d’Economie) \\ 91128 Palaiseau, France \\ Tel: 331693330 18, E-mail: jean-francois.laslier@polytechnique.edu
}

\begin{abstract}
André Blais
Université de Montréal (Département de science politique)

C.P. 6128, succursale Centre-ville, Montréal QC H3C 3J7, Canada

Tel: 1514 343-6111, E-mail: andre.blais@umontreal.ca
\end{abstract}

May 2012

\footnotetext{
'We thank the French Agence Nationale de la Recherche (Project "2 Tours”, coordinator: Annie Laurent), the Social Sciences and Humanities Research Council of Canada (Project “Making Electoral Democracy Work”, coordinator: André Blais), the Center for the Study of Democratic Citizenship, and the Centre pour la Recherche Economique et ses Applications (CEPREMAP) for their financial support.
} 


\begin{abstract}
The paper proposes a way to measure mechanical and psychological effects of majority runoff versus plurality electoral systems in candidate elections. Building on a series of laboratory experiments, we evaluate these effects with respect to the probability of electing a Condorcet winner candidate. In our experiment, the runoff system very slightly favours the Condorcet winner candidate, but this total effect is small. We show that this is the case because the mechanical and psychological effects tend to cancel each other out. Compared to plurality, the mechanical effect of runoffs is to systematically advantage the Condorcet winner candidate, as usually assumed; but our study detects an opposite psychological effect, to the disadvantage of this candidate.
\end{abstract}


Most of the literature about electoral systems is based on Maurice Duverger's intuitions.i Duverger claims that electoral systems have systematic effects (hence the well-known "laws") on the structure of electoral competition. In particular, the plurality rule entails a two-party system whereas majority runoff leads to multiparty competition. Duverger argues that this can be explained by the conjunction of two effects: a mechanical effect and a psychological effect.

The mechanical effect, which takes place after the vote, is the process by which a distribution of votes is transformed into a distribution of seats. This effect is purely mechanical because it results from the strict application of the provisions of the electoral law. The psychological effect, which takes place before the vote, stems from the anticipation by voters and political actors of the mechanical effect. Because actors know the distortion entailed by the transformation of votes into seats, they adapt their behaviour so as to make votes count. ${ }^{\mathrm{iii}}$ This is commonly viewed as strategic voting on the side of voters and strategic entry on the side of parties and candidates.

Duverger's focus was on parliamentary elections. ${ }^{\text {iv }}$ In this note, we defend the view that his distinction between mechanical and psychological effects is useful in other contexts, and we propose an adaptation to candidate elections. In such a context, only one person is to be elected. So, rather than focusing of the number of seats won by the different parties, our analysis will focus on the types of candidate which are elected. In particular, we evaluate the performance of different voting rules in selecting the Condorcet winner candidate $(\mathrm{CW})^{\vee}$, and measure the strength of the mechanical and psychological effects of electoral systems using as a criterion their propensity to elect this type of candidate. 
To assess these effects, we build on a series of laboratory experiments on candidate elections held under plurality and majority runoff rules. Most of the empirical tests that have been conducted so far about Duverger's hypotheses were done using cross country comparisons based on observational studies. ${ }^{\text {vi }}$ While these studies are very valuable, the comparison of the mechanical and psychological effects across voting rules is nevertheless difficult. Indeed, these studies suffer from the weakness that countries not only differ with respect to their electoral institutions, but also with respect to other features which are very likely to influence electoral outcomes, such as the distribution of voter preferences or past electoral records. We propose to complement these studies by resorting to laboratory experiments. Indeed, voter preferences, together with the voting rule, are precisely what can be controlled in the laboratory. Other authors have used experiments to study voting rules, but to the best of our knowledge, they have not explicitly tackled the issue of the comparison of mechanical and psychological effects across voting rules. ${ }^{\text {vii }}$ In this note, we propose an original analysis, sorting out the mechanical and psychological effects of voting rules using such data.

We build on a series of laboratory experiments having elections held under plurality and majority runoff rules, where the distribution of voter preferences over a fixed set of candidates is given and fixed. We compare the probability that a Condorcet winner is elected in runoff vs. plurality elections. The total effect of the runoff system versus the plurality system is the difference in the $\mathrm{CW}$ election probability when voters vote under runoff, compared to when they vote under plurality. We then propose to decompose this total effect into its mechanical and psychological components. Note that we focus exclusively on psychological effects on voters, as candidates' positions are fixed. 
What are the theoretical expectations about the sign and the size of these effects? Regarding the total effect, one of the major claims of supporters of runoff elections is that they make it easier for median $\mathrm{CW}$ candidates to win. viii So we expect the total effect of the runoff effect to be positive. Regarding the mechanical effect of the run-off electoral system, it is unambiguously favorable to the Condorcet Winner (compared to the plurality electoral system). Indeed, in the runoff system, the Condorcet winner is elected whenever he is ranked first or second on the first round (because the CW wins by definition in the pair-wise comparison defined by the run-off), whereas in the plurality system, wins only if he is ranked first. So taking the votes as constant, the mechanical effect is positive. Let us now consider the psychological effect. It depends on how voters' behavior differs across the two voting rules, therefore its sign is a priori ambiguous. Yet, we believe that the intuition might rather suggest this effect to be positive: if one candidate is made more likely to win through the mechanical effect of the electoral system, one might at first sight expect that the voters' reaction to this system (the psychological effect) will be to make him even more likely to win. Our objective is to test these predictions, by offering a way to measure these effects in the lab.

\section{The experimental protocol}

We use data from the laboratory experiments (23 sessions) done by Blais et al.. ${ }^{\text {ix }}$ Groups of 21 subjects (63 subjects in six sessions) are recruited in Paris, Lille (France) and Montreal (Canada). ${ }^{x}$ Each group votes under the two systems: plurality and majority runoff ${ }^{\mathrm{xi}}$, subjects voting in series of four consecutive elections with the same electoral rule.

In each election, there is a fixed number of candidates, located at distinct positions on an axis that goes from 0 to 20 : candidate $A$ is located at position 1 , candidate $B$ at position 6 , 
candidate $C$ at position 10 , candidate $D$ at position 14 and candidate $E$ at position 19 . These positions remain the same through the whole session. Subjects are assigned randomly drawn positions on the same 0 to 20 axis. They draw a first position before the first series of four elections, which they keep for the whole series. After the first series of four elections, the group moves to the second series of four elections, held under a different rule, for which participants are assigned new positions (which again will be kept for the whole series). For each series, there are a total of 21 positions (from 0 to 20) and each of the 21 participants has a different position (draw without replacement; for large groups of 63 voters, three subjects are located in each position). The participants are informed about the distribution of positions: they know that each possible position is filled exactly once (or thrice in sessions with 63 subjects) but they do not know by whom. Besides, they know their own position. Voting is anonymous. The results of each election (scores of all candidates and identity of the elected candidate) are announced after each election.

The participants are informed from the beginning that one of the 8 elections will be randomly chosen as the "decisive" election, which determinates payments. They are also told that they will be paid 20 Euros (or Canadian dollars) minus the distance between the elected candidate's position and their own assigned position in that election. ${ }^{\text {xii }}$ For instance, a voter whose assigned position is 11 will receive 10 Euros if candidate $A$ wins in the decisive elections, 12 if $E$ wins, 15 if $B$ wins, 17 if $D$ wins, and 19 if $C$ wins. We thus generate single-peaked preference profiles on the 5 candidates set. We will refer to candidates $A$ and E as "extreme", and candidates B and D as "moderates". Since this setting is onedimensional and voters are distributed uniformly along this axis, candidate $\mathrm{C}$ is located at the median voter's position, and hence is the Condorcet winner. ${ }^{\text {iii }}$

\section{Measuring mechanical and psychological effects in candidate elections}


Total effect. In those 23 sessions, we ran a total of $23^{*} 4=92$ elections under each voting rule. The extreme candidates were never elected. ${ }^{\text {xiv }}$ The CW candidate was elected in $49 \%$ of the plurality elections. ${ }^{\mathrm{xv}}$ He was either directly elected (on the first round) or present in the run-off in $58 \%$ of the $2 \mathrm{R}$ elections. ${ }^{\text {.vi }}$ There is thus a weak, $58-49=+9$ percentage points, positive total effect of runoff (over plurality) with respect to the election of the CW candidate. However, the effect is not statistically different from $0 .{ }^{\text {xvii }}$

[Insert graph 1 about here]

The total effect can be visualized on Graph 1, which displays, for each voting rule, the percentage of elections where the Condorcet winner is ranked first, second and third or below (for runoff elections, this refers to first rounds). On the left hand side of this graph, one can see that the CW is ranked first (and thus is the winner) in $49 \%$ of the plurality elections. On the right hand side of this graph, one can see that in the first rounds of runoff elections, the $\mathrm{CW}$ is ranked first $37 \%$ of the time, and second $21 \%$ of the time, which makes him a winner in $37+21=58 \%$ of those elections.

We now propose a way to decompose this total effect into its mechanical and psychological components. This decomposition will help understand why the null total effect obtains.

Mechanical effect. In Duverger's setting, the mechanical effect refers to the transformation of votes into seats. In our candidate elections, this translates into the transformation of votes, by the voting rule, into winning and losing candidates, keeping individual votes constant. The mechanical effect is thus defined as the difference between the probability that the CW candidate is elected applying the runoff rule on actual plurality votes, and the 
actual observed probability of the CW candidate's victory when applying the plurality rule on the same plurality votes.

What is the expected sign of this mechanical effect? As noted in the introduction, under plurality the $\mathrm{CW}$ is elected if he is ranked first according to the obtained scores. Under the runoff system, he is elected if he is one of the top two candidates on the first round (provided that no other candidate obtains an absolute majority, which never happened in the data). Indeed, whenever the CW makes it to the second round, by definition, a majority of the voters prefer him over his opponent, whoever this opponent may be. The mechanical effect is therefore always positive: the election of the $\mathrm{CW}$ is more frequent under runoff than under plurality, given the distribution of votes.

To quantify the mechanical effect, we examine the 92 plurality elections in our dataset. For each of those elections, we consider the scores obtained by the 5 candidates, and we apply the runoff system. In this counterfactual simulation, we find that the $\mathrm{CW}$ candidate would be elected in $71 \%$ of the cases if the runoff rule were applied to plurality votes. Keeping the plurality votes constant, moving from plurality to runoff increases by $71-49=22$ percentage points the probability that the $\mathrm{CW}$ candidate is elected. These numbers can be visualized on Graph 1 . On the left hand side of this graph, one can see that in plurality elections, the $\mathrm{CW}$ is ranked first $49 \%$ of the time, and second $22 \%$ of the times. The mechanical effect corresponds to the probability that the $\mathrm{CW}$ is ranked second in plurality elections, as indicated on the graph.

Psychological effect. Keeping Duverger's interpretation, the psychological effect stems from the fact that people vote differently under runoff than they would do under plurality. We define the psychological effect of runoff vs. plurality as the difference in electoral outcomes 
due to the fact that voters behave differently in runoff and plurality elections, keeping the mechanical effects of the (runoff) electoral system constant. The psychological effect is thus defined as the difference between the probability that the CW candidate is elected applying a runoff rule on actual runoff votes and the probability that he would be elected applying a runoff rule on actual plurality votes.

Note that the sign of the psychological effect is a priori ambiguous, since it depends on how voters vote under the two rules. What is observed in the data? We know that the CW candidate wins $58 \%$ of the runoff elections. We also know that the same CW candidate would win $71 \%$ of the time with the same runoff system but using the distribution of votes observed in plurality elections. As a consequence, the psychological effect is negative: the effect is $58-71=-13$ percentage points, as can be seen on Graph 1. ${ }^{\text {xiii }}$ This means that voters are less inclined to vote for the $\mathrm{CW}$ candidate in runoff than in plurality elections.

We see that the mechanical and psychological effects partially cancel each other out, yielding a weak non significant positive net impact. In runoff elections, the CW candidate benefits from the fact that he is certain to win if he makes it to the second round, but he is disadvantaged by the weaker support that he is able to garner in the first round (compared to plurality elections).

\section{Why is the psychological effect negative?}

As noticed earlier, the sign of the psychological effect is a priori ambiguous. We build on previous individual-level analyses of these experiments by Van der Straeten et al. to propose an explanation for this observed negative psychological effect. ${ }^{\text {xix }}$ In our experimental setting, subjects are asked to vote in series of four elections, during which 
everything is kept constant except that voters are, at each date, informed of the scores obtained by all candidates. By observing sequences of elections, we can see, in the lab, how each voter changes her votes and adapts to a voting rule. Van der Straeten et al. 2010 have shown that voters' adaptation through time amounts to voters coordinating on two candidates in plurality elections and on three candidates in runoff elections. ${ }^{x x}$ More exactly, from the second election in the series onward, voters tend to choose to support the candidate closest to them in the subset of the 2 (plurality elections) or 3 (runoff elections) viable candidates, as disclosed by the announcement of the previous election results. ${ }^{\mathrm{x} i}$

What is to be expected regarding the psychological effect if voters behave this way? In runoff elections, there are three viable candidates. At the first date, extreme candidates are observed to receive few votes, so that they do not belong to this subset of viable candidates, which is composed of candidates B, C and D. As a consequence, their supporters gradually desert them in favour of the two moderate candidates (but not in favour of $\mathrm{C})$. Thereby, the $\mathrm{CW}$ candidate remains among the viable candidates, but is more and more often ranked third, which weakens his chances to be elected by the runoff system. Indeed, on average over the 23 sessions, his probability of being elected is 0.67 at the first date, 0.57 at the second, 0.59 at the third, and 0.48 at the fourth.

On the contrary, in plurality elections, there are only two viable candidates. At the first date, one pair of candidates emerges as being viable, and the votes after that focus on this pair. Which candidates initially emerge appears to be largely due to chance, among candidates $B, C$, and $D .{ }^{x \times i i}$ Therefore, if candidate $C$ initially belongs to the emerging pair, he remains part of it, maintaining his chances to be elected. In those elections, we do not observe any clear time trend regarding candidate C's prospect of being elected: on average 
over the 23 sessions, his probability of being elected is 0.54 at the first election, 0.37 at the second, 0.48 at the third, and 0.57 at the fourth.

Thus, in a counterintuitive fashion, the CW candidate is disadvantaged by the larger subset of three viable candidates fostered by runoff elections, relatively to the restricted subset of two viable candidates in plurality elections. In runoff elections, the CW candidate is certain to be viable. But because there are three viable candidates, supporters of the non viable extreme candidates are more likely to move to the moderate candidate that is closer to their own position, thus weakening the CW candidate's chances of making it to the second round. In the plurality elections, because there are only two viable candidates, some of these extreme candidate supporters are willing to vote for the CW candidate, whenever the moderate candidate on their side of the axis is not one of the two viable candidates.

\section{Conclusion}

We have reported on a series of 23 experimental sessions in which participants were invited to vote in a total of 184 elections, 92 under plurality rule and 92 under a majority runoff rule.

We hope this note contributes to a better understanding of the effects of the runoff system in candidate elections. One of the major claims of supporters of runoff elections is that they make it easier for median CW candidates to win. ${ }^{\text {xiii }}$ This claim is not really supported by our data, as the percentage of $\mathrm{CW}$ candidate victories in these experiments is only nine points higher in runoff than in plurality elections, and the effect is not significantly different from 0 . It remains to be seen whether the same pattern would hold under different distributions 
of candidates and voter positions ${ }^{\text {xxiv }}$ but these results suggest that the runoff bias in favour of median candidates may be weaker than expected.

Our study confirms the usefulness of Duverger's famous distinction between mechanical and psychological effects. We have seen that the total effect of runoff (compared to plurality) is weak only because the mechanical and psychological effects tend to cancel each other. It is true that the mechanical effect of runoffs is to systematically advantage CW candidates, exactly as usually assumed. But our study has detected an opposite psychological impact, to the disadvantage of such candidates. ${ }^{x \times v}$

The usual expectation is that psychological effects amplify mechanical ones. This is the case when voters in plurality elections refrain from voting for weak parties that are bound to be disadvantaged by the electoral system. This study has uncovered an instance where the two effects contradict each other. This is a reminder that we should not take for granted that the two effects work in the same direction. More research is needed to determine under what set of conditions such a pattern holds.

Finally this study highlights the advantages of the experimental approach when it comes to ascertaining the impact of electoral systems. This approach is particularly useful in sorting out the specific role of mechanical and psychological effects, where counterfactuals are needed. 


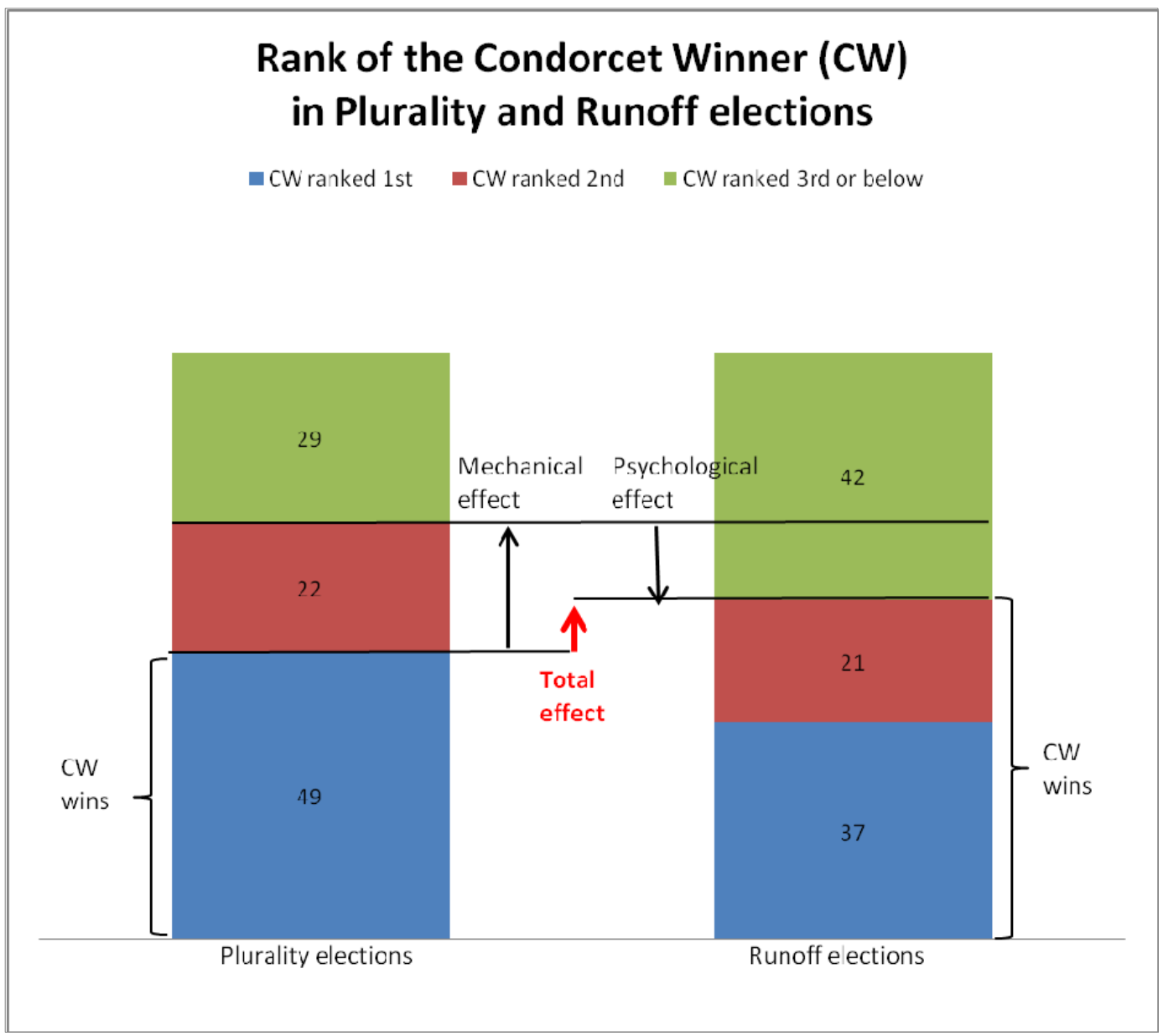

Total effect: CW wins in runoff $(58 \%)-C W$ wins in plurality $(49 \%)=+9$ points

Mechanical effect: CW wins with plurality votes and runoff rule (71\%) - CW wins with plurality votes and plurality rule $(49 \%)=+22$ points

Psychological effect: CW wins runoff votes and runoff rule $(58 \%)-C W$ wins with plurality votes and runoff rule $(71 \%)=-13$ points

Graph 1: The Measurement of Electoral System Effects 
ii Maurice Duverger, Les partis politiques (Paris : Armand Colin, 1951).

iii Gary W. Cox, Making Votes Count: Strategic Coordination in the World's Electoral Systems (Cambridge: Cambridge University Press, 1997).

${ }^{\text {iv }}$ Duverger, Les partis politiques.

${ }^{\mathrm{v}} \mathrm{A}$ Condorcet winner (CW) is an alternative defeating any other alternative in a pair-wise comparison using the majority rule.

${ }^{\text {vi }}$ See for example André Blais, Romain Lachat, Airon Hino, and Pascal Doray-Demers, 'The mechanical and psychological effects of electoral systems', Comparative Politics, forthcoming, on elections in Japan and Switzerland, and Christine Fauvelle-Aymar and Michael S. Lewis-Beck, 'TR v. PR: French Double-Ballot Effects', Electoral Studies 27 (2008), 400-406, on French local elections.

${ }^{\text {vii }}$ For example, series of laboratory experiments have been run on three candidate elections where a majority of voters is split between two majority-preferred candidates, to examine the propensity of different voting rules to elect the minority-preferred candidate. Under the plurality voting rule, several articles study various public coordinating devices, such as pre-election polls or repeated elections, see Dan S. Felsenthal, Zeev Maoz, and Amon Rapoport, 'Tacit Cooperation in Three Alternative Noncooperative Voting Games: A New Model of Sophisticated Behavior under the Plurality Procedure', Electoral Studies, 7 (1988), 143-161; Robert Forsythe, Roger B. Myerson, Thomas A. Rietz and Robert Weber, 'An Experiment on Coordination in Multicandidate Elections: the Importance of Polls and Election Histories', Social Choice and Welfare, 10 (1993), 223-247; Robert Forsythe, Roger B. Myerson, Thomas A. Rietz and Robert Weber, 'An Experimental Study of Voting Rules and Polls in Three-Way Elections', International Journal of Game Theory, 25 (1996), 355-383. Rietz examine the effects of runoff elections in these split-majority electorates (Thomas A. Rietz, 'Three-way Experimental Election Results: Strategic Voting Coordinated Outcomes and Duverger's Law', in Charles R. Plott and Vernon L. Smith, eds., The Handbook of Experimental Economic Results (Amsterdam: Elsevier Science, 2008), pp. 889-897). Morton and Rietz, comparing runoff and plurality elections, show that the minority candidate is less likely to be elected under runoff than under plurality elections (Rebecca B. Morton and Thomas A. Rietz, 'Majority Requirements and Minority Representation', NYU Annual Survey of American Law (2008)). Forsythe et al. study approval voting and the Borda rule as well (Forsythe et al., 'An Experimental Study of Voting Rules and Polls in Three-Way Elections’ ). 
viii André Blais, 'The debate over electoral systems', International Political Science Review, 12 (1991), 239-260.

ix André Blais, Jean-François Laslier, Annie Laurent, Nicolas Sauger and Karine Van der Straeten, 'One-round versus Two Round Elections: an Experimental Study', French Politics, 5 (2007), 278286.

${ }^{\mathrm{x}}$ In Montreal and Paris, subjects are students (from all fields) recruited from subject pools (subject pool from the CIRANO experimental economics laboratory in Montreal, and from the Laboratoire d'Economie Expérimentale de Paris in Paris). In Lille, the experiments took place in classrooms, during a first year course in political science.

${ }^{\mathrm{xi}}$ Under the plurality system, each voter votes for one candidate; the candidate getting the highest number of votes is elected (ties are broken randomly). Under the majority runoff system, on a first round, each voter votes for one candidate. If a candidate gets an absolute majority, he is elected. If not, one proceeds to a second round between the two candidates having obtained the highest two numbers of votes in the first round (ties are broken randomly). On the second round, each voter votes for one candidate; the candidate getting the highest number of votes is elected (ties again are broken randomly).

xii Participants are also paid a fixed sum of 5 Euros for showing up at the experiment.

xiii Note that if subjects were to vote sincerely in plurality elections (or in the first round of a runoff election), the distribution of votes among candidates would be almost uniform. In expectation (with ties broken randomly), the extreme candidates $\mathrm{A}$ and $\mathrm{E}$ would each receive 4 votes, each of the moderate candidates B and D would get 4.5 votes, and the Condorcet winner $\mathrm{C}$ the remaining 4 votes.

xiv All the results that are reported in this paper collapse the experiments held in Canada and France. The patterns are very similar in the two countries. They also merge sessions where the first series of elections is held under plurality and the second series under run-off systems (11 sessions), and those where the reverse order is used (12 sessions). The results turn out to be the same whether a given rule is utilized first or second.

xv During the experiment, ties were broken randomly. In the analysis, for reasons of consistency (see below), in case of such a tie, we reason in terms of probabilities. Consider for example the following scores: A:0, B:7, C:7, D:6, E:1 in a plurality election. There is a tie between candidates B and C. We then compute that with probability $1 / 2$, candidate $\mathrm{B}$ (or C) is elected. 
xvi As in plurality elections, we take care of actual ties by reasoning in terms of probability (cf. footnote XV). Besides, to compute the effects of runoff, we assume that the CW candidate is elected whenever he is present in the runoff. This is indeed the case in more than $95 \%$ of the elections in our experiments. Consider for example the following scores: A:0, B:8, C:6, D:6, E:1 in the first round of a runoff election. There is a tie between candidates $\mathrm{C}$ and $\mathrm{D}$ to decide which candidate will go to the runoff. We then compute that with probability $1 / 2$ the runoff is between $B$ and $C$, in which case $C$ is elected with probability 1 , and with probability $1 / 2$, the run-off is between $B$ and $D$, in which case $C$ is not elected. With such a distribution of votes, we say that $C$ is therefore elected with probability $1 / 2$. We do this to have a consistent method when we perform counterfactual simulations.

xvii Preliminary tests have shown that outcomes under plurality and outcomes under the runoff rule within the same session are not correlated. If one is to assume that observations within series of elections are also independent, the appropriate test is a proportion test on two independent samples, where $\mathrm{C}$ is elected in 45 cases out of 92 in plurality elections, and in 53 cases out of 92 in runoff elections. The test statistics is 1.18 , with a two-tailed p-value of 0.24 . The difference is not significant. Now, because of some learning and coordination effects going on within series of elections (see section 3.), observations within series are likely to be correlated. In that case, we rather take as the observational unit the average probability for the $\mathrm{C}$ candidate to be elected within a series of elections. The two-tailed Student's t-test p-value is 0.46: again we cannot reject the hypothesis that the means are the same in the two samples.

xviii We perform similar tests as for the total effect (see footnote XVII), treating the two samples of plurality and runoff elections as independent. If we consider all elections as independent, C is elected in 53 cases out of 92 in runoff elections, and he would be elected 67 times out of 92 is we applied the run-off system on actual plurality votes. The test statistics for a proportion test is -2.17 , with a onetailed p-value of 0.015 . Now, rather taking as the observational unit the average probability for the C candidate to be elected within a series of elections, we also perform a Student test. The one-sided Student's t-test p-value is 0.11 : we accept at $11 \%$ the hypothesis that the psychological effect is negative.

${ }^{\text {xix }}$ See Karine Van der Straeten, Jean-François Laslier, Nicolas Sauger and André Blais, 'Strategic, Sincere and Heuristic Voting under Four Election Rules: An Experimental Study’, Social Choice and Welfare, 35 (2010), 435-472. 
${ }^{x x}$ We computed the average effective number of candidates at each date, for each voting rule. For plurality elections, this number drops from 4.08 at the first election, to 3.3 at the second, 2.88 at the third, and 2.53 at the last. For runoff elections, the average effective number of candidates is 4.28 at the first election, 3.54 at the second, 3.33 at the third, and 3.2 at the last.

${ }^{x x i}$ This behaviour is consistent with voters voting according to Cox's $M+1$ rule, where $M$ is the magnitude of the district. Indeed, even if only one candidate is finally elected in our candidate elections, the magnitude of the run-off system can be seen as equal to two, if viability is determined by the access to the run-off. Note that under plurality voting for one's preferred candidate among the two viable candidates coincides with fully rational strategic voting, whereas under runoff elections this behaviour (sincere voting within a restricted menu of 3 viable candidates) is not consistent with voters being fully rational strategic (for example, because there is no point in voting for a candidate who is sure to be part of the runoff); see Cox, Making Votes Count: Strategic Coordination in the World's Electoral Systems. In Van der Straeten et al., 'Strategic, Sincere and Heuristic Voting under Four Election Rules: An Experimental Study’, we explicitly test for the hypothesis of fully rational voters, and conclude that the behavioural rule described here (sincere voting within a restricted menu) outperforms the rational model in explaining the data.

xxii This can be explained by the fact that at the first elections of each series, a large proportion of voters votes sincerely. If voters vote sincerely, the distribution of votes among candidates is almost uniform (see footnote XIII).

xxiii See Blais, 'The debate over electoral systems'.

xxiv Morton and Rietz study three candidate elections, where a majority of voters are equally split between two close majority-preferred candidates, and the remaining voters prefer a third candidate (Morton and Rietz, Majority Requirements and Minority Representation'). They show that the minority candidate is less likely to be elected under runoff than under plurality elections. Indeed, in plurality elections, the majority voters may fail to successfully coordinate on one of the two majority candidates, whereas in runoff elections, since one of the two majority candidate is always part of the runoff (when there is no direct winner on the first round), the Condorcet loser cannot win. These divergent results are due, we believe, to the different preference distribution and candidate locations in the two experiments. Whereas Morton and Rietz's study essentially features a coordination game 
between the two groups of majority voters, ours describe a situation with a more fragmented electorate, where the Condorcet winner can be "squeezed" between two moderate candidates.

${ }^{\mathrm{xxv}}$ In our laboratory experiment, we detect a strong psychological effect. How is it expected to compare to what would happen in real world elections? In the experiment, monetary payoffs are used to induce preferences over the set of candidates. The nature of those monetary-induced preferences may be different from voters' true political preferences, and people might be more tactical in our experimental setting than in real world elections. Furthermore, in our experiment, elections are repeated by series of fours, allowing subjects some time to adapt and coordinate. Lastly, we use students as subjects, who are likely to have stronger cognitive skills than non-student subjects, and therefore may engage in more strategic thinking. We therefore believe that, compared to real elections, our experimental results probably provide an upper bound for the size of the psychological effect. 